\title{
Intralesional Microemulsions for Effective Dermal Delivery of Chondroitinase: Formulation, Characterisation and Evaluation
}

\author{
Landge Anil ${ }^{1}$, Krishnamoorthy Kannan ${ }^{1 *}$ \\ 1 Department of Pharmacy, Annamalai University, Annamalainagar- 608002, Tamilnadu, India
}

\begin{abstract}
The rationale behind the microemulsion (ME) formulation was to achieve the efficacy of intralesional delivery and permeability of chondroitinase (CHASE) along with enhanced stability over conventional delivery mode and thus patient compliance. The formulation proceeded with the pseudo-ternary phase diagrams construction to identify microemulsions regions and to establish unique ratio of oil surfactants and aqueous phase. The components used for microemulsion formulation were oleic acid as oil phase, Tween 80 and propylene glycol as surfactantcosurfactant mixture and phosphate buffer $\mathrm{pH} 7.4$ as aqueous phase. The concentration of CHASE in microemulsions was $2.96 \mathrm{U} / \mathrm{mL}$ which was stabilised with $1 \mathrm{M}$ trehalose solution $(\mathrm{w} / \mathrm{w})$. The physicochemical properties of microemulsion were determined. The localization of CHASE within the dermal membrane was determined by in vitro permeability study using excised porcine ear skin. The permeation and the penetration properties of CHASE loaded microemulsion were compared with stabilised aqueous solution of CHASE for varied duration.
\end{abstract}

Keywords: Chondroitinase, intralesional, dermal delivery, in-vitro permeability.

\section{INTRODUCTION}

Chondroitinase ABC (chondroitinase, cABC, ChABC or CHASE) is an enzyme with systematic name chondroitin $A B C$ lyase that specifically acts as chondroitin depolymerizer and also effective on other proteoglycans viz. dermatan sulfate, keratan sulfate and hyaluronate in lowering their levels in irregular extracellular matrix (ECM) formation during cartilage repair process in burns and accident, without disturbing other ECM components. Proteoglycans are the molecules with strong negative charge that attract positive ions

*Corresponding Author: Krishnamoorthy Kannan, e-mail: egkkannan@yahoo.co.in

Landge Anil ORCID Number: 0000-0003-0522-660X

Krishnamoorthy Kannan ORCID Number: 0000-0003-1567-5759

(Received 16 October 2019, accepted 28 November 2019) 
and drag water ions into ECM during cartilage repair process. However, overproduction of proteoglycans inhibits the production of collagen II. The high levels of proteoglycans and low collagen II levels results in cartilage formation with poor biochemical and mechanical strength compared to native cartilage. The treatment of cartilage constructs with CHASE results in more collagen II production, thus the mechanical properties of the repaired cartilage would be closer to that of native articular cartilage. This concept is also applicable for efficient ECM mass formation with the optimum level of proteoglycans and collagen in case of skin recovery after burns and accident.

Intralesional drug delivery is an approach in which medications are injected percutaneously into skin lesion more specifically, at epidermal and dermal membrane with minimal systemic effects and for faster therapeutic effect. The sub-epidermal depot establishment to bypasses the superficial barrier zone is the rationale of this therapy. Here skin enable to deposit medication in the dermal layer as a reservoir and medicaments would be delivered over duration of time, thus achieving prolonged therapy with the avoidance of adverse effects of systemic therapy. ${ }^{1}$

Microemulsion (ME) is drug delivery systems with several advantages such as high stability, enhanced drug solubility, manufacturing ease including enhanced percutaneous penetration of drugs. ${ }^{2}$ These microemulsions loaded with specific drugs if given intralesionally, could exert the potential enhancing effect than the conventional therapy to treat lesions like keloids and hypertropic scars (HSc) till deeper part of skin via percutaneous route. ${ }^{3,4}$ The interaction of oil with the lipids in the stratum corneum results in enhanced fluidity thus increased drug mobility and penetration of surfactants through the skin enhances cutaneous delivery of drug by increasing the partition coefficient of the drug between skin and formulation medium so that drug can be incorporate efficiently at target site ${ }^{5}$. Based on these facts work was aimed to formulate an intralesional microemulsion system for percutaneous delivery of CHASE enzyme. Thus, based on our earlier studies, a stable colloidal system was composed of oleic acid as oil phase, Tween 80 and propylene glycol as surfactantcosurfactant mixture and phosphate buffer ( $\mathrm{pH} 7.4)$ as aqueous phase along with stabilised CHASE enzyme as drug entity ${ }^{6}$. The prepared formulation were evaluated for its physicochemical properties including in vitro release and $e x$ vivo skin retention studies, physical and microbiological stability were evaluated and compared with CHASE solution in phosphate buffer $\mathrm{pH}$ 7.4. 


\section{METHODOLOGY}

\section{Materials}

The enzyme chondroitinase $\mathrm{ABC}$ (CHASE), reported here, was isolated from Proteus penneri SN5, a novel and non-virulent strain. It was further purified, lyophilised and characterised as initial study performed previously. ${ }^{7}$ Sodium phosphate buffer solution pH 7.4 (PBS) was procured from Fresenius Kabi, Pune (India). All substances, chemicals and solvents used during study were analytical grade and procured from Sisco Research Laboratories Pvt. Ltd., Mumbai (India).

\section{Development of Microemulsion Formulations}

\section{Selection of oil, surfactant, and cosurfactant}

Based on the preformulation and solubility studies performed previously. ${ }^{6}$ Oleic acid, Tween 80 and propylene glycol (PG) and phosphate buffer solution (PBS) pH 7.4 was used as components in microemulsion formulation. These excipients are listed under GRAS category (generally regarded as safe) for injectable formulations by US FDA.

\section{Construction of pseudo-ternary phase diagrams}

Pseudo-ternary phase diagrams were constructed using CHEMIX school 7.0 software. The surfactant and cosurfactant used were Tween 80 and PG, having nonionic and hydrophilic nature. The pseudo-ternary phase diagrams of oil, surfactant, cosurfactant, and PBS pH 7.5 were constructed using phase titration method to obtain the components and their concentration ranges resulted as microemulsion region with large existence. ${ }^{8}$ The blend of surfactant with cosurfactant was prepared in specific weight ratios (1:1 and 2:1). The blend of surfactant and cosurfactant $\left(\mathrm{S}_{\text {mix }}\right)$ was then mixed with oil at ambient temperature $\left(25^{\circ} \mathrm{C}\right)$. The ratios of oil to Smix were varied as 9:1, 8:2, 7:3, 6:4, 5:5, 4:6, 3:7, 2:8, and 1:9 (w/w) for each phase diagram. By using magnetic stirrer (Remi Equipments Pvt. Ltd. Mumbai, India) vigorous stirring of each mixture was performed with the drop wise addition of $\mathrm{PBS} \mathrm{pH} 7.4$ at same time at $25^{\circ} \mathrm{C}$. The heating was avoided during the preparation and it was followed with visual observation of each mixture for transparency. These samples were remarked in the phase diagram as points. The region occupied by these points was named as the microemulsion region. All trials were performed in triplicates. 


\section{Process optimisation of $\mathrm{o} / \mathrm{w}$ type microemulsion}

The microemulsion formulations were selected at desired component ratios in view of oil in water type microemulsion formulation with the identification of microemulsion region as per ternary phase diagram. The specific concentration range implying o/w type microemulsion was found to be $1: 5$ for oil and $S_{\text {mix }}$ as per preliminary trial batches. Certain formulation within this ratio with Oil$\mathrm{S}_{\text {mix }}-\mathrm{PBS} \mathrm{pH} 7.4$ was prepared and the process for the preparation of microemulsion was optimized by central composite design method. The impact of variable factors such as stirring speed (200 to $800 \mathrm{rpm}$ ) and time (5 to $20 \mathrm{~min}$ for each stirring speed), over the globule size was considered as response ${ }^{9}$.

\section{Central Composite Design as Experimental Design in process optimisation of microemulsion}

Response surface methodology (RSM) based central composite design (CCD) is a combined technique of mathematics and statistics in designing the experiments and to investigate the factors of process including their interaction between and among variables to find optimum suitable condition to design the model. ${ }^{10} \mathrm{~A}$ factorial $\mathrm{CCD}$ for different factors along with their replicates at the centre point was used for optimisation studies. The variables used were stirring speed (200 to $800 \mathrm{rpm}$ ) and time (5 to $20 \mathrm{~min}$ for each stirring speed) at five coded levels $(-\alpha,-1,0,+1,+\alpha)$ as shown in Table 1 .

Table 1. Real and coded variables used for process optimisation in central composite design (CCD).

\begin{tabular}{|l|c|c|c|c|c|}
\hline \multirow{2}{*}{ Name of independent variables } & \multicolumn{5}{|c|}{ Levels } \\
\cline { 2 - 6 } & Axial (- $\alpha)$ & $\begin{array}{c}\text { Lower } \\
(\mathbf{- 1})\end{array}$ & Central & $\begin{array}{c}\text { Higher } \\
(+\mathbf{1})\end{array}$ & $\begin{array}{c}\text { Axial } \\
(+\alpha)\end{array}$ \\
\hline Stirring speed (rpm) & 75.74 & 200 & 500 & 800 & 924.26 \\
\hline Time (min) & 1.89 & 5 & 12.5 & 20 & 23.11 \\
\hline
\end{tabular}

\section{Preparation of microemulsions}

To prepare the drug loaded microemulsions required quantity of CHASE (370.38 U/mg activity) at the concentration of $2.96 \mathrm{U} / \mathrm{mL}$ [CS degrading unit, $\mathrm{CSU}]$ in presence of $1 \mathrm{M}$ trehalose was dissolved in the mixture of Tween 80 and propylene glycol (2:1). It was followed with slow addition of oleic acid to form a transparent blend. Then the PBS pH 7.4 was added to the clear oilsurfactant solution drop by drop. The o/w microemulsions containing CHASE were obtained under stirring the mixture using magnetic stirrer (Remi Equip- 
ments Pvt. Ltd. Mumbai, India) at $25^{\circ} \mathrm{C}$ with optimized stirring speed and duration. ${ }^{11}$ The evaluation of developed microemulsion was performed further on the basis of zeta potential, globule size, \% permeability and \% drug release.

In order to obtain an aqueous solution CHASE (370.38 U/mg activity) at the concentration of $2.96 \mathrm{U} / \mathrm{mL}$ [CS degrading unit, CSU] with $1 \mathrm{M}$ trehalose was dissolved in PBS $\mathrm{pH} 7.4$.

\section{Characterization of Microemulsion Formulations}

\section{Surface Morphology by TEM}

Surface morphology of globules was observed by means of transmission electron microscopy (TEM) (LVEM5, Delong Instruments, Canada) at $100 \mathrm{kV}$. The optimized microemulsion was diluted 10 times with distilled water. A drop of diluted sample was placed on a 200-mesh film grid to dry at room temperature. The sample was further stained with $2 \%$ phosphotungstic acid solution. Further, it was allowed to dry for 5 min before observation under the electron microscope. ${ }^{12}$

\section{Globule Size, zeta potential and Polydispersity Index (PDI)}

The average globule size and PDI of microemulsions were determined by a laser-scattering method (Nano ZSß 90, Malvern). To avoid multi-scattering phenomena, the samples were diluted suitably with distilled water. The droplet size of the diluted microemulsions was not significantly changed. These investigations were performed as per manufacturer's specifications.

\section{Viscosity, pH and Refractive Index (RI)}

The viscosity of the formulation was measured by using Oswald-type viscometer (Techniko 841, D) while the $\mathrm{pH}$ of microemulsions was determined using a pH meter (Systronics, MK VI). The procedure was repeated three times and the average was taken for calculation. The refractive indices were determined to evaluate the isotropic nature of microemulsions by means of Digital Abbe refractometer (Rudolph Research J257, USA). The refractive index was measured under by placing a drop of microemulsion on the lens of refractometer and observation was done. All measurements were performed at $25 \pm 0.5^{\circ} \mathrm{C}$.

\section{Dye solubility test and dilutability}

This test specifically performed to determine the type of microemulsion. About 4 to 5 drops of methylene blue (water-soluble dye) was added to the test tube containing micro emulsion formulation and visual observation was done after 5 min. ${ }^{13}$ The microemulsion were further diluted in 1:10 and 1:100 ratios with double distilled water to check if the system shows any signs of separation. ${ }^{14}$ 


\section{Syringeability and injectability}

The evaluation of syringeability and injectability was performed on qualitative basis by using insulin syringe. The ease with which the formulation pass through the needle was considered as the basis to qualify syringeability while injectability was evaluated on the basis of the ease with which the formulation was injected into excised porcine ear skin tissue weighing about 2.0 g which was earlier processed under in vitro permeation. ${ }^{15-16}$ About $1 \mathrm{~mL}$ of formulation was drawn into a insulin syringe with a 30 gauge needle (AccuShot, SPM Medicare) and injected into the muscle. The assessment of syringeability and injectability was performed based on the following scores:

$\bullet+++$ Easily passed/injected

$\cdot++$ Moderate

$\bullet+$ Difficult

\section{Sterilization and Control of the Sterility of the Microemulsions}

Blank and CHASE loaded microemulsions were sterilized by aseptic filtration method through $0.22 \mu \mathrm{m}$ pore-size disposable syringe filter (Minisart, Sartorius) under Class II Laminar airflow Cabinet (Cleanair, Chennai). ${ }^{17}$ The sterilized formulations were kept in sterile vials until completion of all experiments. After sterilization process and at the end of the 12 months the sterility testing of the microemulsions was checked to determine the presence of viable forms of microorganisms. To carry out sterility test, $100 \mu \mathrm{l}$ of formulation was inoculated on Blood and Eosin Methylene Blue agar medium (Himedia) by using Drigalski's loop. Escherichia coli ATCC 25922 strains was used to control the agar mediums for positive control. The plates were incubated in the incubator (ILECO, Chennai) for $48 \mathrm{~h}$ at $37^{\circ} \mathrm{C}$ and bacterial colony counting techniques were used to evaluate sterility. All the experiments were carried out in triplicates. ${ }^{18}$

\section{Thermodynamic Stability}

\section{Centrifugation}

The microemulsion formulations were centrifuged at 3500 rpm using centrifuge (REMI, Mumbai, India) for $30 \mathrm{~min}$ and the phase separation is detected if any. ${ }^{19}$

\section{Freeze - thaw Cycle}

These microemulsions were further subjected for six alternate heating and cooling cycles between $25^{\circ} \mathrm{C}$ and $-4^{\circ} \mathrm{C}$ with storage at each temperature for not less than $24 \mathrm{~h}$ and assessed for their physical instability like phase separation, precipitation or any colour change. ${ }^{19}$ 


\section{Drug content estimation}

The microemulsions were diluted with PBS to obtain required drug concentration; the absorbance was determined using UV spectrophotometer (Systronics 2202) at $232 \mathrm{~nm}$. Against placebo formulation treated in the similar manner as blank. ${ }^{6}$

Concentration of sample $=($ Absorbance of sample $*$ Concentration of standard) / Absorbance of standard.

\section{Skin penetration and percutaneous delivery}

\section{Collection and processing of skin tissue}

The skin penetration and percutaneous delivery of CHASE microemulsions were assessed in an in vitro model of porcine ear skin, as per earlier performed studies. ${ }^{20}$ Briefly, the porcine ear skin was collected anonymously from local abattoir. For anonymously collected pig skin samples from slaughter house, approval of institutional Review Board is not required. The tissue was transported to the laboratory in transporting fluid Dulbecco's Modified Eagle Medium (DMEM). It was further thoroughly washed with water and wrapped in cover of aluminium foil and stored in deep freezer. The skin was processed within $24 \mathrm{~h}$. The skin tissue was washed with water and further it was mounted on a Franz diffusion cell (diffusion area of $1.44 \mathrm{~cm}^{2}$ ), with the stratum corneum facing donor compartment and the dermis facing the receptor compartment. ${ }^{21}$ The latter compartment was filled with saline solution $(0.9 \% \mathrm{NaCl})$ with a water jacket $32 \pm 1^{\circ} \mathrm{C}$.

\section{In vitro skin permeation (percutaneous) study}

The $10 \mu \mathrm{l}$ of the CHASE microemulsion formulations was injected just beneath of stratum corneum using an insulin syringe with needle of 30 gauges. At 6 and $12 \mathrm{~h}$ post-injection of microemulsion, removal of excess formulation on skin surfaces was washed thoroughly with distilled water and wiped by means of cotton swab. The stratum corneum (SC) was separated from the remaining epidermis (E), dermis (D) and skin sections by performing tape stripping technique. The skin was stripped with 10-12 pieces of adhesive tape, the initial one was discarded, and the next one containing the SC were immersed in Eppendorf containing $4 \mathrm{~mL} \mathrm{PBS} \mathrm{pH} \mathrm{7.4,} \mathrm{vortexed} \mathrm{and} \mathrm{bath} \mathrm{sonicated} \mathrm{for} 15 \mathrm{~min}$ and this solution was filtered using a $0.22 \mu \mathrm{m}$ membrane. Further, the remained [E $+\mathrm{D}]$ membrane were cut in small pieces, vortexed and sonicated for $30 \mathrm{~min}$. The resulting mixture was then filtered using a $0.22 \mu \mathrm{m}$ membrane, and these both filtrate (SC) and [E + D] was further assayed to determine CHASE content at $232 \mathrm{~nm}$ by UV spectrophotometer. Aqueous solution of CHASE $(0.3 \% \mathrm{w} / \mathrm{w})$ stabilised with $1 \mathrm{M}$ trehalose in PBS $\mathrm{pH} 7.4$ was used as control formulation. ${ }^{21}$ 


\section{Stability Studies}

The formulation under investigation includes the enzyme as biological entity. Hence CHASE microemulsions prepared in the present study were refrigerated for storage. Stability on storage under the following conditions was assessed according to ICH guidelines for stability studies on biopharmaceuticals. ${ }^{6}$ The optimised formulation was packaged in glass vials and stored at $5 \pm 1^{\circ} \mathrm{C}$ in the refrigerator and $25 \pm 2^{\circ} \mathrm{C}$ at room temperature for 2 months. Samples were withdrawn at the end of $1^{\text {st }}$ and $2^{\text {nd }}$ month from both storage conditions. They were investigated for changes in clarity, precipitation, phase separation, viscosity, $\mathrm{pH}$, globule size, zeta potential, and drug content. ${ }^{22}$ The experiments were repeated in triplicates.

\section{RESULTS AND DISCUSSION}

\section{Selection of oil, surfactant, and cosurfactant}

The HLB value of Tween 80 is 15 and for propylene glycol it is almost not applicable. As per concern o/w microemulsion, usually high HLB surfactant should match with low HLB co-surfactant. ${ }^{23}$ In this study, oleic acid used as oil phase, tween 80 as surfactant and propylene glycol as cosurfactant and PBS pH 7.4 solutions as water phase in o/w type microemulsions formulation. Oleic acid has been approved for clinical use in parenteral based formulations for a long time. ${ }^{24-25}$ due to its tissue compatibility and high skin permeability. Tween 80 and propylene glycol were selected as an ideal surfactant since non ionic surfactants and cosurfactants do not undergo ionisation at any extent in solution. They are also approved for their use in parenteral formulations by US FDA. The presence of cosurfactants also contributes its role in maintaining the efficient flexibility of the interfacial film. ${ }^{26}$

\section{Construction of pseudoternary phase diagrams}

In the present study, phase diagrams were constructed to select the concentration range of components for the microemulsions, and the marked areas indicate the clear and viscous microemulsion region (Fig. 1). The major driving force for the release and the penetration of the drug into skin was appreciated with lower surfactant mixture content and this was demonstrated by the thermodynamic activity of drugs in microemulsion. ${ }^{27-28}$ The lower concentration of surfactant in dispersed systems essentially enhances drug release rate and skin permeability. ${ }^{29}$ The individual studies also reported that the formulation containing maximum amount of water with optimum surfactant mixture ratio contributes in highest skin flux and permeability coefficient. Thus, the water content ranged between $60-80 \%$ and $10-30 \%$ of $\mathrm{S}_{\text {mix }}$ probably would be the 
efficient ratio to obtain cutaneous delivery of microemulsion. The domain of microemulsion was investigated by visual inspection in terms of clarity and fluidity. It is well known fact that by increasing concentration of Tween 80 incorporation of water can be increased but drug solubility decreases while by increasing concentration of PG drug solubility increases but incorporation of water decreases. Hence the highest microemulsion area was obtained with ratio of 2:1 and thus selected for further studies. The phase diagrams of different microemulsions are shown in Figure 1.

Ternary Phase Diagram for Microemulsion

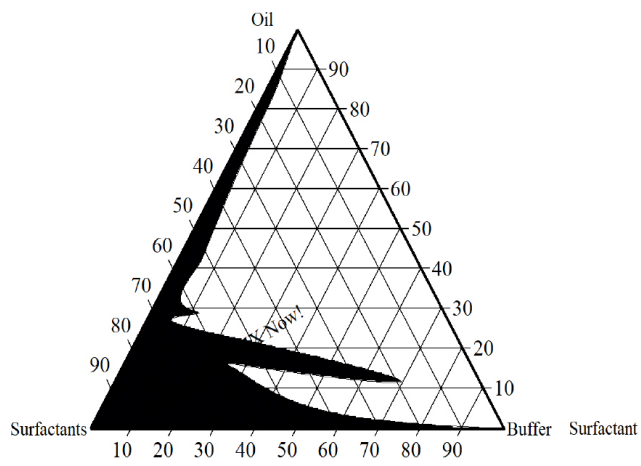

Ternary Phase Diagram for Microemulsion

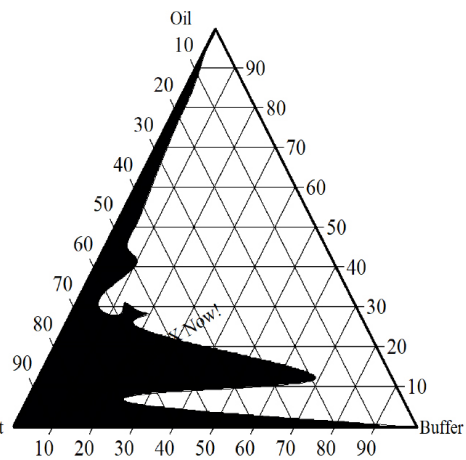

A

B

Figure 1. Pseudo-ternary phase diagrams of the oil-surfactant-water system $1: 1(A)$ and $2: 1$ (B) weight ratios of Tween 80 to propylene glycol at $25^{\circ} \mathrm{C}$. The dark area represents microemulsion regions.

\section{Process optimisation of $\mathrm{o} / \mathrm{w}$ type microemulsion by central composite design (CCD)}

After applying the CCD design for the process optimization of microemulsion, the results indicated that the magnetic stirring speed and time is having profound effect on the globule size reduction in microemulsion. The magnetic stirring speed and duration were found the crucial parameters in effective globule size for o/w type microemulsion with considered ratio. The results of this process are summarised as below in Table 2. 
Table 2. The experiments design trial used for process optimisation for effective globule size

\begin{tabular}{|c|c|c|c|}
\hline No. & Stirring speed $(\mathbf{r p m})$ & Time $(\mathbf{m i n})$ & Globule size $(\mathbf{n m})$ \\
\hline 1 & 500 & 12.5 & 126.54 \\
\hline 2 & 500 & 23.11 & 123.86 \\
\hline 3 & 500 & 12.5 & 126.12 \\
\hline 4 & 800 & 20 & 118.36 \\
\hline 5 & 500 & 10.8 & 124.28 \\
\hline 6 & 500 & 12.5 & 125.94 \\
\hline 7 & 924 & 12.5 & 117.88 \\
\hline 8 & 500 & 12.5 & 126.74 \\
\hline 9 & 76 & 12.5 & 138.44 \\
\hline 10 & 200 & 20 & 133.16 \\
\hline 11 & 200 & 5 & 130.25 \\
\hline 12 & 800 & 5 & 123.88 \\
\hline 13 & 500 & 12.5 & 126.27 \\
\hline
\end{tabular}

\section{Analysis of variance and fitting of data to the model}

In order to clarify the impact of the independent variables according to the results, response surface and $3 \mathrm{D}$ plots of the quadratic polynomial model were created by varying two of independent variables (within the experimental range) for studying the combination effect on response. It showed the statistical significance of adding new terms step by step in increasing order. It provided accounts of variation and associated P-values (Prob $>$ F). The model was selected based on the highest order that was significant (P-value small) and not aliased, on lack of fit (P-value > 0.10) and the Pred-R ${ }^{2}$ value of 0.9289 was in rational agreement with the $\mathrm{Adj}$. $\mathrm{R}^{2}$ of 0.9815 . The difference was less than 0.2. Value of lack of fit was $0.159>0.05$ (not significant) showing that the hypothesis of significance of fitting was rejected for RSM method. ANOVA results are illustrated in Table 3 . 
Table 3. Analysis of variance of the regression coefficients of the quadratic equation for globule size.

\begin{tabular}{|c|c|c|c|c|c|c|}
\hline Source & $\begin{array}{l}\text { Sum of } \\
\text { Squares }\end{array}$ & df & $\begin{array}{l}\text { Mean } \\
\text { Square }\end{array}$ & F Value & $\begin{array}{l}\text { p-value } \\
\text { Prob }>F\end{array}$ & $\begin{array}{c}\text { Model } \\
\text { significancy }\end{array}$ \\
\hline Model & 403.027 & 5 & 80.61 & 128.38 & $<0.0001$ & significant \\
\hline $\begin{array}{l}\text { A-Stirring } \\
\text { speed }\end{array}$ & 381.518 & 1 & 381.52 & 607.65 & $<0.0001$ & \\
\hline B-Time & 0.403 & 1 & 0.40 & 0.64 & 0.4493 & \\
\hline$A B$ & 2.941 & 1 & 2.94 & 4.68 & 0.0672 & \\
\hline$A^{2}$ & 3.225 & 1 & 3.22 & 5.14 & 0.0578 & \\
\hline$B^{2}$ & 12.945 & 1 & 12.94 & 20.62 & 0.0027 & \\
\hline Residual & 4.395 & 7 & 0.63 & & & \\
\hline Lack of Fit & 3.983 & 3 & 1.33 & 12.90 & 0.159 & not significant \\
\hline Pure Error & 0.412 & 4 & 0.10 & & & \\
\hline $\begin{array}{l}\text { Corrected } \\
\text { Total }\end{array}$ & 407.422 & 12 & & & & \\
\hline
\end{tabular}

The analysis result by ANOVA was with 95\% confidence displaying $\mathrm{F}$ value model was 128.38 and if the value of $\mathrm{P}$ lower than 0.05, that means the predicted model was substantial. Moreover, the lowest Press value 28.97 of this model in comparison with others ensures fitting of this model. All the responses observed for nine runs were fitted to various models using response surface methodology (Design Expert software). It was observed that the best fitted model was polynomial quadratic. In primary observation, the $3 \mathrm{D}$ surface plot behaviour gives information that the globule size could be minimised by incresing stirring rate for longer time (Fig. 2).

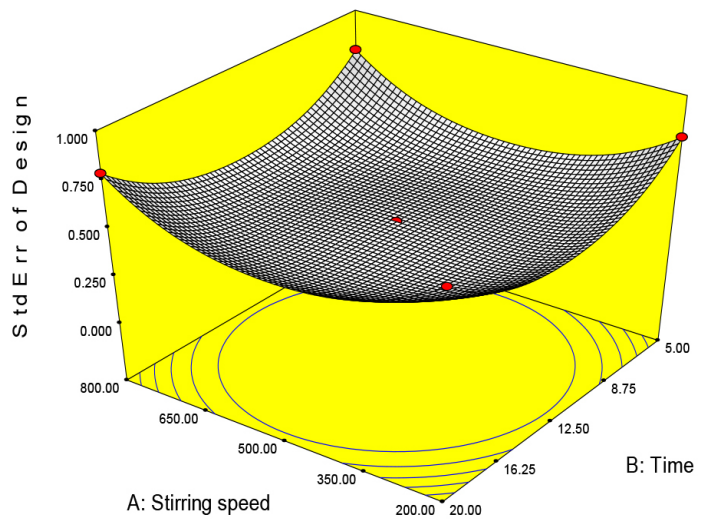

Figure 2. The 3D surface plot behaviour indicating interaction between stirring rate and time. 


\section{Optimised Condition Specifications}

Obtaining the best conditions for the $\mathrm{o} / \mathrm{w}$ microemulsion formulation with effective globule size was obtained by setting each variable in range via numerical optimization. Accordingly, the first most solution was selected as per higher desirability resulted with minimal globule size. Thus, the experimental value of optimised stirring speed of 800 rpm with 20 min duration was $118.78 \pm 0.27$ $\mathrm{nm}$ (predicted value: $118.10 \mathrm{~nm}$ ) as given in Table 4 .

Table 4. Validation of most desirable solution obtained while optimization.

\begin{tabular}{|c|c|c|c|c|c|c|}
\hline \multirow[b]{2}{*}{ No. } & \multirow{2}{*}{$\begin{array}{c}\text { Stirring } \\
\text { speed (rpm) }\end{array}$} & \multirow{2}{*}{$\begin{array}{l}\text { Time } \\
(\min )\end{array}$} & \multicolumn{2}{|c|}{ Globule size (nm) } & \multirow[b]{2}{*}{ Desirability } & \multirow[b]{2}{*}{ Remark } \\
\hline & & & $\begin{array}{l}\text { Predicted } \\
\text { value }\end{array}$ & $\begin{array}{l}\text { Experimental } \\
\text { value }\end{array}$ & & \\
\hline 1 & 800 & 20.0 & 118.10 & $118.78 \pm 0.27$ & 0.9893 & Selected \\
\hline 2 & 800 & 18.5 & 118.72 & & 0.9593 & \\
\hline 3 & 800 & 5.0 & 119.37 & & 0.9277 & \\
\hline 4 & 800 & 6.3 & 119.69 & & 0.9119 & \\
\hline 5 & 800 & 11.4 & 120.16 & & 0.8890 & \\
\hline
\end{tabular}

\section{Development of CHASE microemulsion formulations}

Parenteral microemulsions may be utilized for the drug targeting and to decrease the toxic effects to tissues..$^{30}$ The potential of parenteral microemulsions has been explored so far primarily to prolong the mean residence time of drugs administered intralesionally [24]. The administration of oil-in-water $(\mathrm{o} / \mathrm{w})$ formulations could be beneficial in the parenteral drug delivery, since the attendance of surfactant and co-surfactant raises permeability, thus improving drug uptake. From pseudo ternary study, surfactant and co-surfactant having 2:1 ratio selected for micro emulsion batches formulation. CHASE which acts as core enzyme drug (activity: $370.38 \mathrm{U} / \mathrm{mg}$ ) was freshly thawed from $-20^{\circ} \mathrm{C}$ by putting it on ice and about $5 \mathrm{mg}$ was immediately dissolved in $5 \mathrm{~mL}$ of $1 \mathrm{M}$ trehalose solution. From this stock solution enzyme drug equivalent to 2.96 units was utilised in microemulsion formulation. According to constant oil: $\mathrm{S}_{\text {mix }}$ ratio (1:5) the batches were developed and evaluated for various tests. The clear microemulsion was obtained without phase segregation after addition of drug and additive. The developed microemulsions were filtered through 0.2 $\mathrm{mm}$ sterile syringe filters under sterile conditions. The sterile microemulsions were kept in sealed sterile vials until the experiment (Fig. 3). The CHASE microemulsions with different composition phases along with their \% weight is summarised (table 5) with pictorial view. 
Table 5. The percentage weight and batch composition of each microemulsion formulation.

\begin{tabular}{|c|c|c|c|}
\hline Formulation code & Oleic acid (\%) & $\begin{array}{c}\text { Tween 80: } \\
\text { Propylene glycol } \\
(\mathbf{2 : 1 )}(\mathbf{\%})\end{array}$ & $\begin{array}{c}\text { Phosphate Buffer } \\
\text { Saline (PBS) pH 7.4 } \\
\mathbf{( \% )}\end{array}$ \\
\hline CHASE ME1 & 3.0 & 15 & 82 \\
\hline CHASE ME2 & 3.5 & 17.5 & 79 \\
\hline CHASE ME3 & 4.0 & 20 & 76 \\
\hline CHASE ME4 & 4.5 & 22.5 & 73 \\
\hline CHASE ME5 & 5.0 & 25 & 70 \\
\hline
\end{tabular}

*The final amount of CHASE in each microemulsion formulation was $2.96 \mathrm{U} / \mathrm{mL}$ [CS degrading unit, CSU].

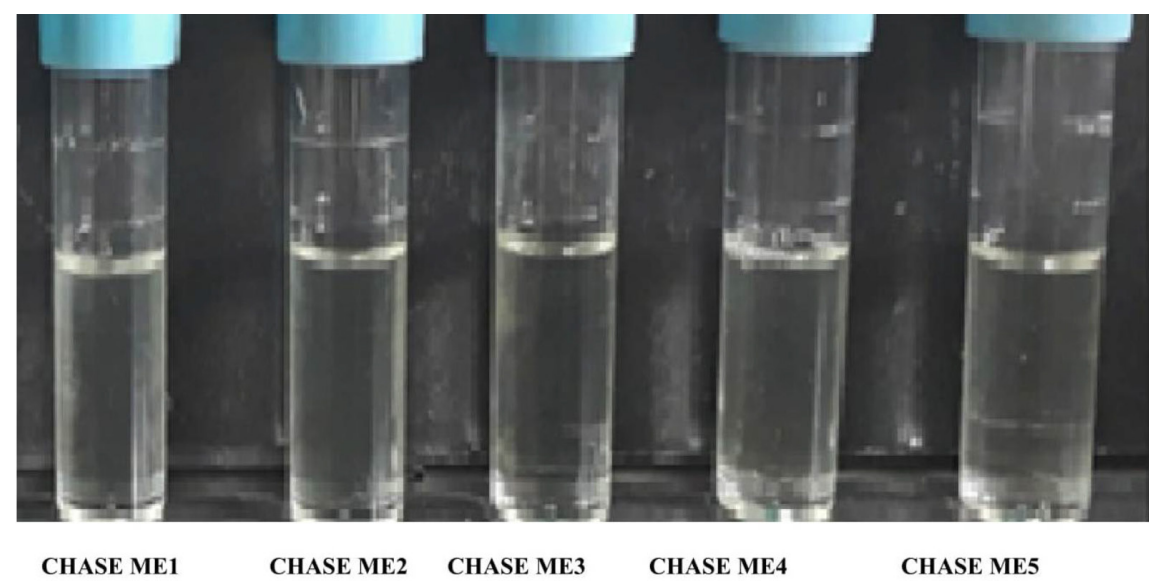

Figure 3. Image of CHASE ME formulations with different phase and \% weight ratio

\section{Characterization of Microemulsion Formulations}

\section{Surface Morphology by TEM}

In principle, when a drop of microemulsion is place on a TEM copper grid and allowed to dry, rearrangement of particles may takes place during drying process. TEM analysis revealed that globules of formulation were almost homogenous and spherical shaped. The globules in the CHASE microemulsion were appeared to be dark spheres with bright background (Fig. 4). These results indicates that a large number of globules were in range of nano size (less than $200 \mathrm{~nm}$ ). It was further concluded that these oil globules were well dispersed in continuous phase without any aggregation. However; the globule size distribution of microemulsion was not uniform. 


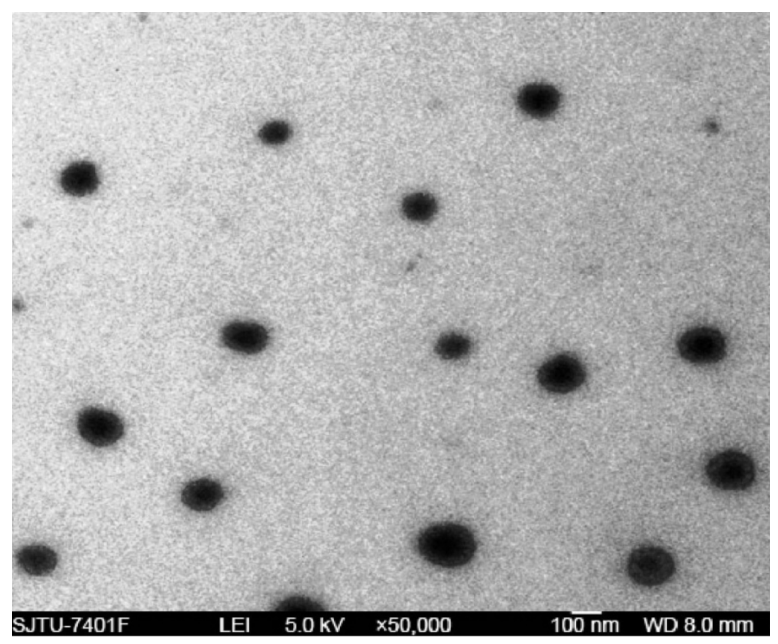

Figure 4. TEM photograph of CHASE ME formulation.

\section{Globule Size, zeta potential and Polydispersity Index (PDI)}

Globule size of microemulsions was found in the range of 108-111 nm (Table 6). This indicated a uniform microemulsion with a narrow size distribution. In addition, droplet size increased in proportion with the oil content while surfactant mixture lowers its content. This phenomenon may be attributed to the expansion of the microemusion oil core, and the high surfactant concentration forcefully reducing the oilwater interfacial tension to reduce droplet size. It also can be seen the range of $\zeta$-potential of -0.117 to -0.123. This negative charge value of $\zeta$-potential was resulted probably due to carboxyl groups of oleic acid, also due to several functional groups with high electronegativity such as hydroxyl, amide and carboxyl groups of CHASE enzyme. The negativity of $\zeta$-potential is a sign of longer stability of microemulsion due to electrostatic repulsion of individual particles. ${ }^{31}$

The polydispersity index (PDI) of the microemulsions was observed in the range of 0.186-0.198 that indicates narrow size distribution of water globules In general, PDI range from 0.01- 0.5 is considered as the narrow size distribution of globules and with PDI > 0.7 indicates very broad size distribution. ${ }^{33}$

\section{Viscosity, $\mathrm{pH}$ and Refractive Index (RI}

The stability of the microemulsion is often governed by its viscosity, i.e., is an expression of the resistance to flow. The viscosity refers the tendency of microemulsion system to form agglomeration. It is fundamental fact that the viscosity of parenteral formulation may also affect the syringeability particularly in case of intralesional route. ${ }^{15}$ Using the equation (1), the viscosity of the 
developed formulated was calculated to be 8.76 to $10.79 \mathrm{cP}$. The viscosity was calculated from the equation:

$\frac{\eta 1}{\eta 2}=\frac{\rho 1 \mathrm{t} 1}{\rho 2 \mathrm{t} 2}-----------$ equation $(1)$

where $\eta_{1}$ and $\eta_{2}$ are the viscosities of the test and the standard liquids, $\rho_{1}$ and $\rho_{2}$ are the densities of the liquids, and $t_{1}$ and $t_{2}$ are the respective flow times in seconds.

The $\mathrm{pH}$ values of microemulsions were varied from the range 5.99 to 6.40 (Table 6). For any therapeutic delivery, such $\mathrm{pH}$ values could be considered in the tolerable/acceptable range. The $\mathrm{pH}$ of the formulation was in an acceptable range for intralesional administration. ${ }^{34}$ The RI of microemulsions was determined which were found in range of 1.3126 and 1.3602 (almost nearer to the RI of the oils used) which demonstrates the isotropy (homogeneity) of the formulation. ${ }^{32}$ These characterisation parameters are detailed in Table 6.

Table 6. Characterisation studies of different CHASE microemulsions (mean $\pm S D, n=3$ ).

\begin{tabular}{|c|c|c|c|c|c|c|}
\hline $\begin{array}{c}\text { Formulation } \\
\text { code }\end{array}$ & $\begin{array}{c}\text { Globule size } \\
(\mathrm{nm})\end{array}$ & $\begin{array}{c}\text { Zeta potential } \\
(\mathrm{mV})\end{array}$ & $\begin{array}{c}\text { Polydispersity } \\
\text { index }\end{array}$ & $\mathrm{pH}$ & $\begin{array}{c}\text { Viscosity } \\
(\mathbf{c P})\end{array}$ & $\begin{array}{c}\text { Refractive } \\
\text { index }\end{array}$ \\
\hline ME1 & $108.86 \pm 1.23$ & $-0.117 \pm 0.005$ & $0.186 \pm 0.006$ & $6.40 \pm 0.01$ & $8.7611 \pm 0.023$ & $1.3126 \pm 0.0001$ \\
\hline ME2 & $109.18 \pm 1.59$ & $-0.120 \pm 0.003$ & $0.194 \pm 0.009$ & $6.34 \pm 0.01$ & $9.2343 \pm 0.014$ & $1.3202 \pm 0.0001$ \\
\hline ME3 & $110.17 \pm 0.21$ & $-0.118 \pm 0.002$ & $0.195 \pm 0.004$ & $6.24 \pm 0.01$ & $9.7888 \pm 0.011$ & $1.3416 \pm 0.0002$ \\
\hline ME4 & $110.79 \pm 0.75$ & $-0.123 \pm 0.006$ & $0.196 \pm 0.004$ & $6.05 \pm 0.05$ & $10.2665 \pm 0.006$ & $1.3584 \pm 0.0002$ \\
\hline ME5 & $109.83 \pm 0.75$ & $-0.118 \pm 0.005$ & $0.198 \pm 0.006$ & $5.99 \pm 0.02$ & $10.7936 \pm 0.012$ & $1.3602 \pm 0.0002$ \\
\hline
\end{tabular}

\section{Dye solubility test and dilutability}

It is also called as the stain test in which specific dye is sprinkled on the surface of the emulsion to confirm the nature of continuous phase. In case of an o/w emulsion there is rapid incorporation of a water-soluble dye into the system whereas w/o emulsion generates microscopically visible clumps. The reverse happens on addition of an oil soluble dye..$^{13-14}$

The microemulsion under examination was transparent and looked blue and almost the same colour as water dyed with methylene blue. This is an indication of uniform and fine dispersion of oil globules in water; to form o/w type microemulsion. There were no signs of phase separation upon dilution of microemulsion formulations in 1:10 and 1:100 ratios with double distilled water. 


\section{Syringeability and injectability}

Syringeability is the ability or an ease withdrawal of formulation from vial before dispensing and injectability refers to the solution performance during injection. The factors such as force or pressure required for injection is also considered. Both these parameters are influenced by the viscosity of the formulations. Viscosity contributes significant challenges in injectability since high viscosity requires high injection force that ultimately leads to cause inevitable pain. High viscous products sometime cause deterrent in completeness of the injection and thus percentage of dose delivered. ${ }^{16}$ No formulation from F1 to F5 showed resistance to syringeability and injectability, moreover these formulations were able to withdraw easily into syringe and injected into the tissue, thereby reducing the potential to create problems during withdrawal of doses or produce pain on injection. The results of syringeability and injectability of all microemulsions are given in Table 7.

Table 7. Data for syringeability and injectability of formulations

\begin{tabular}{|c|c|c|}
\hline Formulation code & Syringeability & Injectability \\
\hline CHASE ME1 & +++ & +++ \\
\hline CHASE ME2 & +++ & +++ \\
\hline CHASE ME3 & +++ & +++ \\
\hline CHASE ME4 & +++ & +++ \\
\hline CHASE ME5 & +++ & +++ \\
\hline
\end{tabular}

\section{Sterilization and Control of the Sterility of the Microemulsions}

Sterilization of the microemulsion formulation for intralesional administration is an important parameter and it can be universally applied to microemulsion formulations with aseptic filtration methods. The suitability of sterilization technique of microemulsions was estimated with bacteria colony counting. At the end of this time period of incubation no cloudy appearance or growth was determined on the agar medium and the developed microemulsions were determined as sterile.

The positive control plates with, E.coli colonies have a characteristic green sheen due to rapid fermentation of lactose \& production of strong acids, caused reduction in the $\mathrm{pH}$ of the EMB agar to form the green metallic sheen (Fig. 5) ${ }^{35}$ 


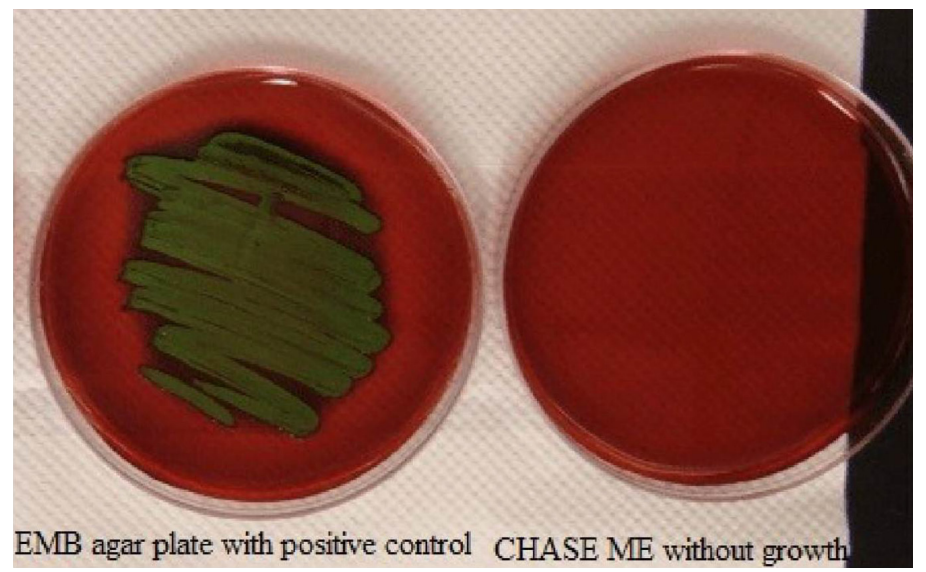

Figure 5. Sterility test on EMB agar indicates the developed microemulsions are sterile.

\section{Thermodynamic Stability}

As the two droplets coalesces with each other to form a single and larger size globule, it results in negative interfacial tension of the newly formed globule, and the system results in negative free-surface energy. To effect zero interfacial tension, the large globule increases its curvature spontaneously and results in two globules of the original size again. This process takes place in continuous manner as the bombardment of globules happens by molecules of dispersion medium. This is a dynamic equilibrium which maintains the microemulsion systems stable. ${ }^{36}$ At the end of $30 \mathrm{~min}$, the developed microemulsions did not show any signs of phase separation and drug precipitation after centrifugation at 3,500 rpm, to alter stability of the formulation.

Below freezing temperature, the ice crystals formation in an o/w type microemulsion may results in elongation and flattening of oil particles. In addition, the hydrophobic portion of the emulsifiers looses their mobility while the hydrophilic portions are "dehydrated" due to the freezing phenomenon of water. If the sample is thawed, release of takes place that migrate rapidly through the microemulsion system. In case of slower rate of re-dissolution of the ingredients, it may generate instability microemulsion system irrelevant to normal temperature processes. ${ }^{13}$ The developed CHASE microemulsion formulations did not appeared with any instability evidences, the overall physical integrity of the formulation was remained unaltered throughout the cycle (Table 8). 
Table 8. Different CHASE microemulsions with thermodynamic stability testing

\begin{tabular}{|c|c|c|c|c|}
\hline $\begin{array}{c}\text { Formulation } \\
\text { code }\end{array}$ & Appearance & Centrifugation & $\begin{array}{c}\text { Freeze-thaw } \\
\text { cycle }\end{array}$ & Inference \\
\hline ME1 & $\begin{array}{c}\text { Clear and } \\
\text { transparent }\end{array}$ & $\mathrm{P}$ & $\mathrm{P}$ & Pass \\
\hline ME2 & $\begin{array}{c}\text { Clear and } \\
\text { transparent }\end{array}$ & $\mathrm{P}$ & $\mathrm{P}$ & Pass \\
\hline ME3 & $\begin{array}{c}\text { Clear and } \\
\text { transparent }\end{array}$ & $\mathrm{P}$ & $\mathrm{P}$ & Pass \\
\hline ME4 & $\begin{array}{c}\text { Clear and } \\
\text { transparent }\end{array}$ & $\mathrm{P}$ & $\mathrm{P}$ & Pass \\
\hline ME5 & $\begin{array}{c}\text { Clear and } \\
\text { transparent }\end{array}$ & $\mathrm{P}$ & $\mathrm{P}$ & Pass \\
\hline
\end{tabular}

P: Complies

\section{Drug content estimation}

The potency of CHASE as drug content in all formulations was found to be in range of 91.71-95.35\%. The actual concentration of CHASE was calculated in range of 2.71 to $2.82 \mathrm{U} / \mathrm{mL}$ of microemulsion formulation (Table 9). These values overall correspond to 339.43 to $352.90 \mathrm{U} / \mathrm{mg}$ of CHASE enzyme. According to literatures, when CHASE having an enzymatic activity of 270 Units/mg protein or more is appreciated in the injectables to target proteoglycans and its appropriate degradation without affecting surrounding tissues. ${ }^{37}$ Thus, the formulated microemulsion of CHASE would be the safe and effective system for drug delivery. The maximum drug content was estimated in CHASE ME4 as $2.82 \mathrm{U} / \mathrm{mL}$ with potency of $95.35 \%(\mathrm{w} / \mathrm{v})$ among all formulations.

Table 9. Concentration of CHASE in different microemulsion as drug content with its potency

\begin{tabular}{|c|c|c|c|}
\hline Formulation code & $\begin{array}{c}\text { CHASE concentration } \\
(\mathbf{U} / \mathbf{m L})\end{array}$ & $\begin{array}{c}\text { CHASE activity } \\
(\mathbf{U} / \mathbf{m g})\end{array}$ & $\begin{array}{c}\text { CHASE potency } \\
(\% \text { w/v) }\end{array}$ \\
\hline ME1 & $2.71 \pm 0.004$ & $339.43 \pm 0.54$ & $91.71 \pm 0.15$ \\
\hline ME2 & $2.74 \pm 0.005$ & $343.01 \pm 0.61$ & $92.68 \pm 0.17$ \\
\hline ME3 & $2.77 \pm 0.003$ & $346.45 \pm 0.35$ & $93.61 \pm 0.10$ \\
\hline ME4 & $2.82 \pm 0.003$ & $352.90 \pm 0.35$ & $95.35 \pm 0.09$ \\
\hline ME5 & $2.79 \pm 0.003$ & $348.88 \pm 0.41$ & $94.27 \pm 0.11$ \\
\hline
\end{tabular}

\section{In vitro skin permeation study}

Compared to aqueous CHASE solution, the microemulsion formulations was significantly enhanced CHASE skin penetration in time course of 6 and $12 \mathrm{~h}$ after injection. The time-course of the in vitro CHASE skin penetration showed 
that when CHASE was injected in the microemulsion form, its concentration in $\mathrm{E}+\mathrm{D}$ membrane was about $60-85 \%$ while concentration in $\mathrm{SC}$ was found 15-20\%. However, the CHASE ME1 shows behaviour almost similar to that aqueous CHASE solution it may be caused due to lower content of permeation enhancer and high aqueous media. The maximal concentrations of CHASE in 6 $\mathrm{h}$ was 22.86 and $34.29 \mathrm{ng} / \mathrm{cm}^{2}$ while in $12 \mathrm{~h} 11.43$ and 34.29 in SC and E+D respectively by CHASE ME1 similar to aqueous CHASE solution. The behaviour of ME2 and ME3 was found almost equal with 53.33 and $40 \mathrm{ng} / \mathrm{cm}^{2}$ in (E+D) compartment at 6 and $12 \mathrm{hr}$ respectively. On the other hand, no CHASE was detected in SC compartment and 66.67ng/cm2 after $12 \mathrm{~h}$ application by ME4 and ME5 almost 2-fold higher than CHASE aqueous solution. The formulation ME4 and ME5 was found in the different compartments were in almost equal concentration as shown (Fig. $6 \mathrm{~A}$ and B).

A

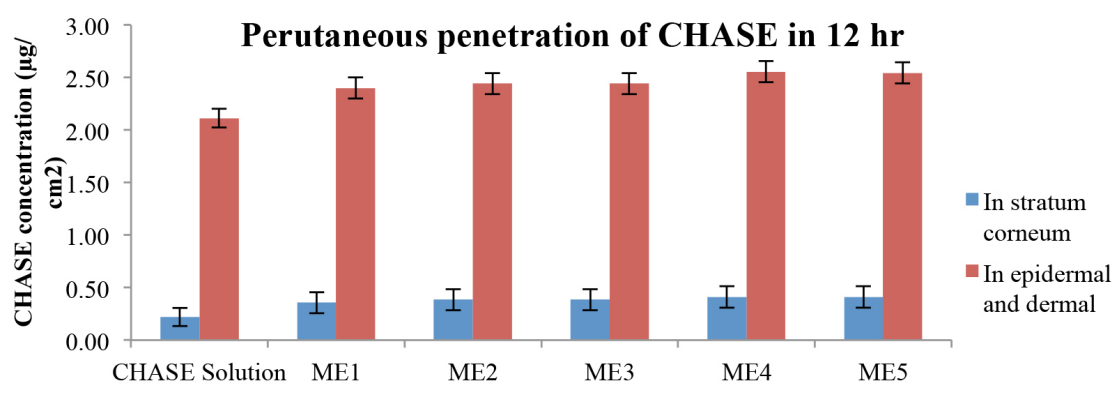

B

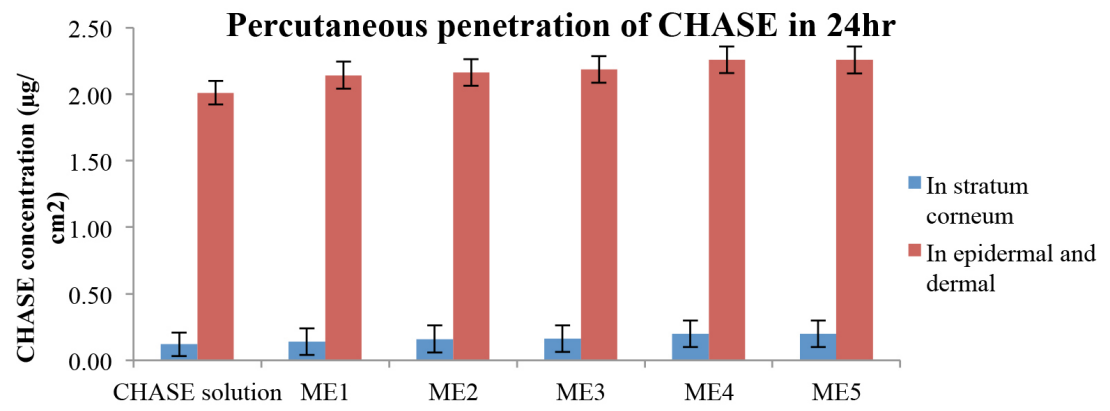

Figure 6. Time-course of the in vitro skin permeation of CHASE incorporated in different o/w type microemulsions in $6 \mathrm{~h}(\mathrm{~A})$ and $12 \mathrm{~h}(\mathrm{~B})$. 


\section{Stability studies}

All CHASE microemulsion formulations, ME1 to ME5 exhibited transparency clarity and no drug precipitation, phase separation or colour change when it was subjected to stability study at $5 \pm 1^{\circ} \mathrm{C}$ in the refrigerator and $25 \pm 2^{\circ} \mathrm{C}$ at room temperature for 2 months. The physical properties like appearance, refractive index, viscosity and $\mathrm{pH}$ were also observed and no significant change was found in these characters. There was no significant change observed in globule size, zeta potential, PDI and drug content at refrigerated condition in first month while slight changes observed in drug content at the end of 2 months. The slight decrease in enzyme potency was evident at the end of 2 months in case of formulations kept at room temperature it is probably due to free fatty acid presence in oleic acid and also responsible in lowering of $\mathrm{pH} .{ }^{38}$ The mean globule size however was not affected during the storage. Thus, the o/w structure of microemulsion and suitable range from 5.8 to 7.0 provided suitable circumstance for avoiding the hydrolysis of drug. The results of stability studies are detailed in Table 10.

Table 10. Stability testing of CHASE ME4 after 1- and 2-month interval at various temperatures of $5^{\circ} \mathrm{C} \pm 3^{\circ} \mathrm{C}$ and $25^{\circ} \mathrm{C} \pm 2^{\circ} \mathrm{C} / 60 \pm 5 \% \mathrm{RH}$.

\begin{tabular}{|c|c|c|c|c|c|c|c|c|}
\hline $\begin{array}{c}\text { Temperature } \\
\left({ }^{\circ} \mathrm{C}\right)\end{array}$ & $\begin{array}{c}\text { Time } \\
\text { interval } \\
\text { (month) }\end{array}$ & Viscosity & $\mathrm{pH}$ & Globule size & $\begin{array}{c}\text { Zeta } \\
\text { potential }\end{array}$ & $\begin{array}{c}\text { CHASE } \\
\text { Concentration } \\
(\mathrm{U} / \mathrm{mL})\end{array}$ & $\begin{array}{c}\text { CHASE } \\
\text { activity } \\
(\mathrm{U} / \mathrm{mg})\end{array}$ & $\begin{array}{c}\text { CHASE } \\
\text { potency } \\
(\% \mathrm{w} / \mathrm{V})\end{array}$ \\
\hline \multirow{2}{*}{$5^{\circ} \mathrm{C} \pm 3^{\circ} \mathrm{C}$} & 1 & $10.7914 \pm 0.007$ & $5.93 \pm 0.009$ & $119.61 \pm 1.67$ & $-0.116 \pm 0.004$ & $2.81 \pm 0.002$ & $352.18 \pm 0.20$ & $95.16 \pm 0.06$ \\
\cline { 2 - 9 } & 2 & $10.7851 \pm 0.006$ & $5.95 \pm 0.014$ & $122.28 \pm 0.69$ & $-0.112 \pm 0.002$ & $2.79 \pm 0.003$ & $349.60 \pm 0.41$ & $94.46 \pm 0.11$ \\
\hline $\begin{array}{c}25^{\circ} \mathrm{C} \pm \\
2^{\circ} \mathrm{C} / 60 \pm \\
5 \% \mathrm{RH}\end{array}$ & 1 & $10.7963 \pm 0.009$ & $5.95 \pm 0.022$ & $122.27 \pm 1.08$ & $-0.113 \pm 0.003$ & $2.77 \pm 0.003$ & $346.45 \pm 0.35$ & $93.61 \pm 0.10$ \\
\cline { 2 - 9 } & 2 & $10.7782 \pm 0.007$ & $5.93 \pm 0.005$ & $123.53 \pm 0.88$ & $-0.118 \pm 0.002$ & $2.75 \pm 0.002$ & $344.16 \pm 0.20$ & $93.33 \pm 0.42$ \\
\hline
\end{tabular}

In summary, we have formulated the microemulsions for the effective intralesional delivery of chondroitinase. The formulations displayed high permeability for dermal delivery through the stratum corneum membrane of skin evidenced by in vitro penetration skin study. The present study can open up a window for dermal application of proteins and enzymes in microemulsion form in treatment of excessive glycosaminoglycans and collagen in ECM responsible for lesions and keloids in deeper membrane of dermis and epidermis. Since the drugs via intralesional route are delivered in similar passion to that of intradermal delivery, it was more fruitful to investigate in vitro permeability studies using porcine ear skin tissue instead of in vivo permeability determination. Moreover, drug release kinetics data is irrational as the enzyme is 
hardly absorbed in systemic circulation. Thus, a better alternative is provided over conventional lyophilised chondroitinase for constitution in terms of efficacy and stability.

\section{ACKNOWLEDGEMENTS}

The authors herewith gratefully acknowledge the financial support by University Grants Commission, New Delhi for UGC-BSR Fellowship (grant number: F-25/1/2014-15(BSR)/7-269/2009(BSR) $7^{\text {th }}$ Oct 2015) during research tenure. Authors also express their sincere gratitude towards Dr S. Selvamuthukumar, Associate Professor, Dept. of Pharmacy, Annamalai University for his support and guidance during the work. 


\section{REFERENCES}

1. Landge, A. V.; Kannan, K. Intralesional delivery of therapeutic peptides and enzymes -A Review. Int. J. Chemtech Res. 2017, 10, 373-383.

2. Shukla, T.; Upmanyu, N.; Agrawal, M.; Saraf, S.; Alexander, A. Biomedical applications of microemulsion through dermal and transdermal route. Biomed. Pharmacother. 2018, 108, 1477-1494.

3. Xiao, Y; Liu, F; Ping, Q; Cai, Hao. The influence of the structure and the composition of water/AOT-Tween 85/IPM microemulsion system on transdermal delivery of 5 -fluorouracil, Drug Dev Ind. Pharm. 2012, 38, 1521-1529.

4. Nastiti, C.; Ponto, T.; Abd, E.; Grice, J. E.; Benson, H.; Roberts, M. S. Topical nano and microemulsions for skin delivery. Pharmaceutics, 2017, 9, 1-25.

5. Salimi, A.; Mohammad, K. H. Enhanced stability and dermal delivery of hydroquinone using microemulsion-based system. Asian J. Pharm. Sci. 2018, 11, 1-10.

6. Landge, A. V.; Kannan, K. Investigation of drug-excipients compatibility for colloidal delivery of therapeutic chondroitinase. J. Global Pharm. Tech. 2019, 11, 16-26.

7. Landge, A. V.; Kannan, K. Optimization of Induction Media for Production of Chondroitinase from Proteus penneri SN5 Using Response Surface Methodology. J. Pharm. Sci. Res. 2018, 10, 2702-2708.

8. Sushma, T; Lalit, M. N., Harshita, S. Encapsulation via microemulsion. In Handbook of Encapsulation and Controlled Release; $1^{\text {st }} \mathrm{ed}$. Mishra, M. Ed.; Taylor and Francis: CRC Press, Florida, 2016; pp 359-384.

9. Flores-Miranda, G.; Valencia-del T. G.; yañez, J. Stability evaluation of $\beta$-Carotene nanoemulsions prepared by homogenization-emulsification process using stearic acid as oil phase. Rev. Mex. Ing. Quim. 2015, 14, 667-680.

10. Myers, R.H; Montgomery, D. The analysis of second-order response surfaces. In Response Surface Methodology: Process and Product Optimization Using Designed Experiments. $3^{\text {rd }}$ ed. Zentralblatt M, Ed.; Wiley: New York, 2012; pp 229-280.

11. Anil, K.; Ahuja, A.; Ali, J.; Baboota, S. Curcumin-loaded lipid nanocarrier for improving bioavailability, stability and cytotoxicity against malignant glioma cells. Drug Deliv. 2016, 23, 214-229.

12. Agrawal, A. G.; Ashok, K.; Gide, P. S. Formulation of solid self-nanoemulsifying drug delivery systems using $N$-methyl pyrrolidone as cosolvent. Drug Dev. Ind. Pharm. 2015, 41, 594-604.

13. Nemichand, S.; Deore, S. Solubility enhancement of Nebivolol by microemulsion technique. J. Young Pharm. 2016, 8, 356-367.

14. Sabale, V.; Vora, S. Formulation and evaluation of microemulsion-based hydrogel for topical delivery. Int. J. Pharm. Investig. 2012, 2, 140-149.

15. Cilurzo, F.; Selmin, F.; Minghetti, P.; Adami, M.; Bertoni, E.; Lauria, S.; Montanari, L. Injectability evaluation: an open issue. AAPS Pharm. Sci. Tech. 2011, 12, 604-609.

16. Golombek, S.; Pilz, M.; Steinle, H.; Kochba, E.; Levin, Y.; Lunter, D. Intradermal delivery of synthetic mRNA using hollow microneedles for efficient and rapid production of exogenous proteins in skin. Mol Ther. 2018, 11, 382-392.

17. Darole, P. S.; Hegde, D. D.; Nair, H. A. Formulation and evaluation of microemulsion based delivery system for amphotericin B. AAPS Pharm. Sci. Tech. 2008, 9, 122-128. 
18. Okur N.Ü.; Özdemir, D. İ.; Kahyaoğlu, Ş. G.; Şenyiğit, Z. A.; Aşıkoğlu, M.; Genç, L.; Karasulu, H. Y. Assessment of aprotinin loaded microemulsion formulations for parenteral drug delivery: preparation, characterization, in vitro release and cytotoxicity studies. Curr. Drug. Deliv. 2015, 12, 668-79.

19. Jaiswal, P.; Aggarwal, G.; Harikumar, S. L.; \& Singh, K. Development of self-microemulsifying drug delivery system and solid-self-microemulsifying drug delivery system of telmisartan. Int. J. Pharm. Investig. 2014, 4, 195-206.

20. Jacobi, U.; Kaiser, M.; Toll, R.; Mangelsdorf, S.; Audring, H.; Otberg, N.; Sterry, W.; Lademann, J.; Porcine ear skin: an in vitro model for human skin. Skin. Res. Technol. 2007, 13, 19-24.

21. Vicentini, F. T.; Simi, T. R.; Del-Ciampo, J. O.;, Wolga, N.O.; Pitol, D. L.; Iyomasa, M. M.; Bentley, M.V.; Fonseca, M. J. Quercetin in w/o microemulsion: in vitro and in vivo skin penetration and efficacy against UVB-induced skin damages evaluated in vivo. Eur. J. Pharm. Biopharm. 2008, 69, 948-57.

22. Saani, S. M.; Abdolalizadeh, J.; Heris, S. Z. Ultrasonic/sonochemical synthesis and evaluation of nanostructured oil in water emulsions for topical delivery of protein drugs. Ultrason. Sonochem. 2019, 55, 86-95.

23. Azeem, A.; Rizwan, M.; Ahmad, F. J.; Iqbal, Z.; Khar, R. K.; Aqil, M.; Talegaonkar, S. Nanoemulsion components screening and selection: a technical note. AAPS Pharm. Sci. Tech. 2009, 10, 69-76.

24. Pontes-Arruda, A. Biological benefits of an oleic acid-rich lipid emulsion for parenteral nutrition. Clin. Nutr. 2009, 4, 19-23.

25. Zhao, H.; Lu, H.; Gong, T.; Zhang, Z. Nanoemulsion loaded with lycobetaine-oleic acid ionic complex: physicochemical characteristics, in vitro, in vivo evaluation, and antitumor activity. Int. $J$. Nanomedicine. 2013, 8, 1959-73.

26. Gurram, A. K.; Deshpande, P. B.; Kar, S. S.; Nayak, U. Y.; Udupa, N.; Reddy, M. S. Role of components in the formation of self-microemulsifying drug delivery systems. Indian J. Pharm. Sci. 2015, 77, 249-257.

27. Manconi, M.; Sinico, C.; Fadda, A. M. Penetration Enhancer-Containing Vesicles for $\mathrm{Cu}-$ taneous Drug Delivery. In Percutaneous Penetration Enhancers Chemical Methods in Penetration Enhancement. $1^{\text {st }}$ ed. Dragicevic, N.; Maibach, H. I. Ed.; Springer: Berlin: 2016, pp 93-110.

28. Yang, J.; Xu, H.; Wu, S.; Ju, B.; Zhu, D.; Yan, Y.; Hu, J. Preparation and evaluation of microemulsionbased transdermal delivery of Cistanche tubulosa phenylethanoid glycosides. Mol. Med. Rep. 2017, 15, 1109-1116.

29. Gupta, S. Biocompatible Microemulsion Systems for Drug Encapsulation and Delivery. Curr. Sci. 2011, 101, pp. 174-188.

30. Date, A.; Nagarsenker, M. Parenteral microemulsions: An overview. Int. J. Pharm. 2oo8, 355, 19-30.

31. Emil, J.; Singhvi, G. Multifunctional nanocrystals for cancer therapy: a potential nanocarrier. In Nanomaterials for Drug Delivery and Therapy. $1^{\text {st }}$ ed. Alexandru, M. G. Ed.; University Politehnica: Bucharest, 2019, pp 91-116.

32. Rakesh K.; Sudhir K.; Sinha V. R. Evaluation and Optimization of Water-in-Oil Microemulsion Using Ternary Phase Diagram and Central Composite Design. J. Disp. Sci. Tech. 2016, 37, 166-172. 
33. Tuğcu-Demiröz, F.; Füsun, A.; Özkul A. Preparation and characterization of bioadhesive controlled-release gels of cidofovir for vaginal delivery. J. Biomater. Sci. 2015, 26, 1237-1255.

34. Maleki, M.; Karimi, G.; Tafaghodi, M.; Raftari, S.; Nahidi, Y. Comparison of intralesional two percent zinc sulfate and glucantime injection in treatment of acute cutaneous leishmaniasis. Indian J. Dermatol. 2012, 57, 118-22.

35. Afsana, T. O. Vaccine Efficacy of a $45 \mathrm{kDa}$ Outer Membrane Protein of Escherichia coli O157:H7 in Mice Models. A dissertation submitted to BRAC University, Dhaka. 2017, pp 23-24.

36. Dahiya, P.; Caggioni, M.; Spicer, P. T. Arrested coalescence of viscoelastic droplets: polydisperse doublets. Philos. Trans. A Math. Phys. Eng. Sci. 2016, 374, 1-32.

37. Taiichi, S.; Takao, M.; Masafumi, Y. Chondroitinase abc for treating disc herniation. European patent no. EP2653168B1, 2011.

38. Terés, S.; Barceló-Coblijn, G.; Benet, M.; Alvarez, R.; Bressani, R.; Halver, J. E.; Escribá, P. V. Oleic acid content is responsible for the reduction in blood pressure induced by olive oil. Proc. Natl. Acad. Sci. USA. 2008, 105, 13811-13816. 